\title{
Propiedades diagnósticas de las definiciones de caso sospechoso de COVID-19 en Chile, 2020
}

\author{
Josefina Aubert', Doris Durán ${ }^{1}$, María José Monsalves ${ }^{1}$, María Francisca Rodríguez¹, Elena S. \\ Rotarou$^{1}$, Jean Gajardo², Tania Alfaro ${ }^{3}$, María Paz Bertoglia ${ }^{4}$, Sergio Muñoz ${ }^{5}$ y Cristóbal Cuadrado 6
}

Forma de citar Aubert J, Durán D, Monsalves MJ, Rodríguez MF, Rotarou ES, Gajardo J, et al. Propiedades diagnósticas de las definiciones de caso sospechoso de COVID-19 en Chile, 2020. Rev Panam Salud Publica. 2021;45:e14 https://doi.org/10.26633/ RPSP.2021.14

RESUMEN

Objetivo. Comparar las propiedades diagnósticas de cinco definiciones de caso sospechoso de COVID-19 utilizadas o propuestas en Chile durante los primeros ocho meses de la pandemia.

Métodos. Se analizaron las propiedades diagnósticas (sensibilidad, especificidad, y valores predictivos positivo y negativo) de tres definiciones de caso sospechoso de COVID-19 utilizadas en Chile entre marzo y octubre del 2020, y dos propuestas de definición alternativas. La muestra fue de 2019 personas con resultados conocidos a la prueba de la reacción en cadena de la polimerasa (PCR) para SARS-CoV-2. Para elaborar el criterio 5 se aplicó una regresión logística escalonada (stepwise) optimizando los valores de sensibilidad y especificidad. Se exploró la asociación de variables demográficas, síntomas y signos con la positividad a la PCR mediante regresión logística multifactorial. Se analizaron diferentes escenarios de positividad y se compararon las curvas ROC.

Resultados. La presencia de anosmia (OR = 8,00; IC95\%: 5,34-11,99) y fiebre (OR = 2,15; IC95\%: 1,28-3,59) y el haber tenido contacto estrecho previo con una persona enferma de COVID-19 (OR = 2,89; IC95\%: 2,163,87 ) se asociaron con un resultado positivo de la PCR. Según el análisis de las curvas ROC, el criterio 5 tuvo la mayor capacidad de discriminación, aunque sin diferencias significativas con los otros cuatro criterios.

Conclusiones. El criterio 5 -basado en la anosmia, el contacto estrecho con personas enfermas de COVID19 y la fiebre como elementos únicos suficientes - tuvo la mayor sensibilidad para identificar los casos sospechosos de COVID-19, aspecto fundamental para controlar la propagación de la pandemia.

Palabras clave Infecciones por coronavirus; virus del SRAS; técnicas de diagnóstico molecular; Chile.

La pandemia de COVID-19 constituye una amenaza para la salud pública en todo el mundo. Esta enfermedad es resultado de la infección por el coronavirus 2 del síndrome respiratorio agudo grave (SARS-CoV-2), notificado por primera vez en diciembre del año 2019 en Wuhan, China (1). En marzo del 2020, la enfermedad ya estaba presente en más de 100 países y la Organización Mundial de la Salud (OMS) la declaró pandemia; cuatro meses después se habían notificado 12068034 casos confirmados en 188 países y territorios de todos los continentes (2).

Los primeros síntomas de COVID-19, que aparecen entre 2 y 14 días (5,2 días en promedio) después de la infección por SARS-CoV-2 $(3,4)$, son fiebre, tos y fatiga (5), con manifestaciones de tos más intensa, disnea y dolor torácico a medida que compromete las vías respiratorias bajas, y rinorrea y odinofagia

\footnotetext{
Facultad de Medicina y Ciencia, Universidad San Sebastián, Santiago, Chile. $\square$ M. José Monsalves, maria.monsalves@uss.cl

2 Facultad de Ciencias para el Cuidado de la Salud, Universidad San Sebastián, Santiago, Chile.

3 Programa de Epidemiología, Escuela de Salud Pública, Universidad de Chile, Santiago, Chile.
}

\footnotetext{
4 Unidad de Nutrición de Poblaciones, Escuela de Salud Pública, Universidad de Chile, Santiago, Chile.

5 Programa de Políticas, Sistemas y Gestión en Salud, Escuela de Salud Pública, Universidad de Chile, Santiago, Chile.

6 Departamento de Salud Pública-CIGES, Facultad de Medicina, Universidad de La Frontera, Temuco, Chile.
} 
al afectar a las vías respiratorias altas. Un considerable número de pacientes con COVID-19 desarrollan trastornos gastrointestinales, como diarrea (6), mientras otros pueden presentar manifestaciones neurológicas, entre las que las alteraciones agudas del olfato (anosmia) y del gusto (disgeusia) son de particular interés por su frecuencia $(7,8)$. Si bien se ha descrito que entre el $30 \%$ y el $45 \%$ de las personas infectadas no desarrollan síntomas, estas representan una fuente importante de transmisión del virus $(9,10)$.

El diagnóstico temprano es fundamental, no solo para realizar el seguimiento del caso y su tratamiento oportuno, sino también para aislar tempranamente a los casos positivos y realizar el seguimiento de sus contactos a fin de reducir las posibilidades de diseminación de la enfermedad y evitar el colapso del sistema de salud (11). El establecimiento de directrices eficaces de salud pública para la identificación temprana de casos sospechosos puede contribuir a predecir con mayor certeza quiénes de ellos tienen mayores posibilidades de evolucionar y llegar a confirmarse como casos de COVID-19, lo que permitiría optimizar el diagnóstico con la prueba de la reacción en cadena de la polimerasa (PCR, por sus siglas en inglés), recurrir al aislamiento preventivo en espera de los resultados, generar alertas tempranas a los contactos secundarios que puedan estar asintomáticos (12), proveer una atención adecuada oportuna y dirigir más acertadamente los limitados recursos sanitarios disponibles (13).

A partir de las recomendaciones de la OMS para enfrentar la COVID-19, el Ministerio de Salud de Chile acometió el fortalecimiento de la vigilancia epidemiológica antes de que se confirmara el primer caso en el país el 3 de marzo del 2020 y se establecieron las definiciones de caso sospechoso, caso probable y caso confirmado (14). Entre enero y octubre de este año, esas definiciones han sufrido modificaciones $y$, aunque la última se aprobó en junio, aún no se han evaluado el rendimiento diagnóstico de esas definiciones y su capacidad predictiva para la COVID-19.

Mientras, la pandemia crece exponencialmente en Chile, que al 4 de julio del 2020 ya alcanzaba los 330183 casos acumulados (15) y en octubre ya superaba los 450000 casos confirmados, con más de 18400 fallecidos (16) y el mayor foco de contagio en su capital, Santiago. La necesidad de contar con una definición de caso sospechoso con mayores probabilidades de confirmarse positivo mediante una prueba de la PCR resulta de vital importancia para la toma de decisiones más acertadas para el control de la pandemia, frenar la cadena de transmisión y disminuir el número de contagios.

En este trabajo se comparan las propiedades diagnósticas de cinco definiciones de caso sospechoso de COVID-19 utilizadas o propuestas en Chile durante los primeros ocho meses de la pandemia.

\section{MATERIALES Y MÉTODOS}

\section{Diseño}

Se analizaron las propiedades diagnósticas (sensibilidad, especificidad y valores predictivos positivo [VPP] y negativo [VPN]) de tres definiciones de caso sospechoso de COVID-19 utilizadas en Chile entre marzo y octubre del 2020 y dos propuestas de definición alternativas.

El análisis se realizó en una submuestra de 2019 personas con examen de PCR para COVID-19 de resultado conocido (positivo o negativo) del total de 48928 participantes en el estudio Monitoreo Nacional de Síntomas y Prácticas COVID-19 en Chile (MOVID-19). Este estudio se basa en un instrumento de autoinforme en línea y busca construir un catastro amplio de los síntomas observados y las prácticas de la población chilena ante la COVID-19. La información generada por el estudio MOVID-19 es longitudinal, ya que solicita a los participantes el registro semanal y tiene un alcance territorial nacional ${ }^{7}$.

Los participantes informaron sobre los síntomas y signos presentados durante la semana en que se realizó el examen. No se consideraron mediciones de seguimiento, ya que la sintomatología predictiva de un diagnóstico positivo en una persona no está sujeta a variaciones en el tiempo.

\section{Definiciones de caso sospechoso analizadas}

Se analizaron las propiedades diagnósticas de cinco criterios de caso sospechoso de COVID-19 (cuadro 1). El primero de ellos (criterio 1) fue el propuesto por las autoridades locales en Chile y establecido mediante el Decreto Ordinario B51-933 del 23 de marzo del 2020 (17), a partir de las recomendaciones de la OMS. Posteriormente, en una minuta publicada el 26 de abril, el Consejo Asesor COVID-19, adscrito al Ministerio de Salud de Chile, propuso una nueva definición de caso sospechoso (criterio 2) (18); aunque esta definición no fue implementada por la autoridad sanitaria nacional, se incluyó en el análisis por el respaldo científico con que cuenta.

También se analizó la definición recomendada por la OMS (criterio 3), incluida en sus reportes de vigilancia; para este estudio, se tomaron en cuenta solo los elementos a y b de la última actualización disponible en el momento del estudio, contenida en el informe del 30 de abril (19).

La cuarta definición de caso sospechoso (criterio 4) se implementó en el país mediante una resolución del Ministerio de Salud el 30 de mayo, que modificó las definiciones anteriores (20); se implementó en el mes de junio y seguía vigente al redactar la revisión final de este artículo en el mes de octubre.

Por último, se analiza una propuesta de caso sospechoso derivada de esta investigación (criterio 5), dirigida a elevar la sensibilidad y mejorar el rendimiento diagnóstico y que permitiría identificar un mayor número de personas que tendrían un resultado positivo a la prueba de la PCR.

\section{Análisis de los datos}

Se analizaron mediante técnicas descriptivas las variables demográficas y los síntomas y signos observados en la muestra, según el resultado a la prueba de la PCR, fuera este positivo (PCR+) o negativo (PCR-). Se estimó la asociación entre las variables y la positividad a la PCR mediante regresión logística múltiple, según la siguiente ecuación:

$$
\begin{aligned}
\log \text { it } P[Y=1 \mid X]= & \beta_{0}+\beta_{1} \text { sexo }+\beta_{2} \text { edad }+\beta_{3} \text { anosmia }+\beta_{4} \text { tos }+ \\
& \beta_{5} \text { diarrea }+\beta_{6} \text { fiebre }+\beta_{7} \text { odinofagia }+ \\
& \beta_{8} \text { cefalea }+\beta_{9} \text { mialgia }+\beta_{10} \text { dolor torácico }+ \\
& \beta_{11} \text { disnea }+\beta_{12} \text { contacto estrecho }
\end{aligned}
$$

Se puede encontrar más información sobre el estudio MOVID-19 y sus métodos en https://www.movid19.cl/somos/sobre/ 


\begin{tabular}{|c|c|c|c|c|}
\hline Criterio 1 & Criterio 2 & Criterio 3 & Criterio 4 & Criterio 5 \\
\hline $\begin{array}{l}\text { a. Viajero: paciente con } \\
\text { enfermedad respiratoria aguda } \\
\text { que presenta fiebre o al menos un } \\
\text { signo o síntoma de enfermedad } \\
\text { respiratoria y con antecedente de } \\
\text { haber viajado o residido en un } \\
\text { país, área o territorio que informa } \\
\text { casos de COVID-19, durante los } \\
14 \text { días previos a los síntomas. } \\
\text { b. Contacto: paciente con } \\
\text { cualquier enfermedad respiratoria } \\
\text { aguda y con antecedente de } \\
\text { haber estado en contacto con un } \\
\text { caso confirmado o sospechoso } \\
\text { de COVID-19, en los } 14 \text { días } \\
\text { previos a los síntomas. } \\
\text { c. Circulación local: paciente con } \\
\text { infección respiratoria aguda que } \\
\text { resida o se encuentre de paso } \\
\text { en una región con circulación } \\
\text { comunitaria del SARS-CoV-2 } \\
\text { y que presenta fiebre (más de } \\
37,8^{\circ} \mathrm{C} \text { ) y al menos uno de los } \\
\text { siguientes síntomas: odinofagia, } \\
\text { tos, mialgia o disnea. } \\
\text { d. Vigilancia: paciente con } \\
\text { infección respiratoria aguda grave } \\
\text { (que requiere hospitalización). }\end{array}$ & $\begin{array}{l}\text { a. Fiebre (temperatura axilar } \\
\text { mayor de } 37,8^{\circ} \mathrm{C} \text { ) sin otra causa } \\
\text { evidente } \\
\text { y/0 } \\
\text { b. Síntomas sugerentes de } \\
\text { infección respiratoria, tales como } \\
\text { mialgia, odinofagia, tos o disnea, } \\
\text { dolor torácico o abdominal, } \\
\text { postración, cianosis, diarrea, } \\
\text { taquipnea } \\
\text { y/o } \\
\text { c. Alteración aguda del olfato } \\
\text { (anosmia) o gusto (disgeusia). }\end{array}$ & $\begin{array}{l}\text { a. Paciente con enfermedad } \\
\text { respiratoria aguda (fiebre y al } \\
\text { menos un signo o síntoma de } \\
\text { enfermedad respiratoria, como } \\
\text { tos y disnea) y con antecedente } \\
\text { de haber viajado o residido } \\
\text { en un lugar con transmisión } \\
\text { comunitaria de COVID-19, } \\
\text { durante los } 14 \text { días previos al } \\
\text { inicio de los síntomas } \\
\text { o } \\
\text { b. Paciente con enfermedad } \\
\text { respiratoria aguda y que haya } \\
\text { estado en contacto con un caso } \\
\text { confirmado o probable de COVID- } \\
19 \text {, en los } 14 \text { días previos al inicio } \\
\text { de los síntomas } \\
\text { o } \\
\text { c. Paciente con enfermedad } \\
\text { respiratoria aguda (fiebre y } \\
\text { al menos un signo o síntoma } \\
\text { de enfermedad respiratoria, } \\
\text { como, tos y disnea, y que } \\
\text { requiera hospitalización) y sin } \\
\text { un diagnóstico alternativo que } \\
\text { explique la presentación clínica. }\end{array}$ & $\begin{array}{l}\text { a. Persona que presenta un } \\
\text { cuadro agudo con al menos dos } \\
\text { de los síntomas de la COVID- } \\
19 \text { (fiebre, tos, disnea, dolor } \\
\text { torácico, odinofagia, mialgia, } \\
\text { escalofríos, cefalea, diarrea, } \\
\text { anosmia o ageusia). } \\
\text { b. Persona con una infección } \\
\text { respiratoria aguda grave que } \\
\text { requiera hospitalización. }\end{array}$ & $\begin{array}{l}\text { a. Toda persona que desarrolle } \\
\text { cualquier combinación de al } \\
\text { menos dos de los siguientes } \\
\text { síntomas: tos, diarrea, odinofagia } \\
\text { o cefalea } \\
\text { y/0 } \\
\text { b. Toda persona que haya } \\
\text { tenido contacto estrecho con un } \\
\text { paciente confirmado de COVID- } \\
19 \text { mediante la prueba de la PCR } \\
\text { y/0 } \\
\text { c. Toda persona que presente } \\
\text { fiebre (temperatura axilar } \\
\text { mayor de } 37,8^{\circ} \mathrm{C} \text { ) sin otra causa } \\
\text { evidente } \\
\text { y/0 } \\
\text { d. Toda persona que presente } \\
\text { manifestación aguda de anosmia. }\end{array}$ \\
\hline
\end{tabular}

Fuente: elaborado por los autores.

Criterio 1: adoptado por el Ministerio de Salud de Chile el 23 de marzo (17); Criterio 2: recomendado por el Consejo Asesor CoVID-19 de Chile el 26 de marzo (18); Criterio 3: recomendado por la Organización Mundial de la Salud en su actualización del 30 abril (19); Criterio 4: adoptado por el Ministerio de Salud de Chile el 30 de mayo (20); Criterio 5: nuevo criterio propuesto.

donde, $\mathrm{P}[Y=1 \mid \mathrm{X}]$ representa la probabilidad de tener un resultado $\mathrm{PCR}+$, dado el conjunto de factores (denotado como X); las variables $\beta_{0}$ a $\beta_{12}$ corresponden a los coeficientes de regresión del modelo ajustado.

Se incluyeron los síntomas referidos por los pacientes en los siete días previos al día en que se informó el resultado positivo o negativo de la prueba de la PCR. Se decidió considerar solo siete días en el modelo final, a partir del análisis de sensibilidad realizado que comparó la asociación de los síntomas y los resultados a la PCR a los 7, 14 y 21 días (cuadro 2), pues no se observaron diferencias al considerar más días.

La nueva propuesta de caso sospechoso (criterio 5) se formuló a partir de una regresión logística escalonada (conocida por su nombre en inglés, stepwise method) mediante la técnica de incorporación (en inglés, forward selection) de todas las variables referidas en la ecuación anterior; se adoptó un nivel de significación $\leq 0,2$ para seleccionar las variables que mejor podrían explicar la positividad confirmada. Se consideraron las variables edad, sexo, contacto estrecho con una persona diagnosticada con la COVID-19, y nueve signos y síntomas asociados con esta enfermedad según la literatura internacional (5): tos, fiebre, cefalea, anosmia, diarrea, dolor torácico, mialgia, odinofagia y disnea.

Posteriormente, se realizó el análisis de las propiedades diagnósticas de los cinco criterios en estudio referidos en el cuadro 1, empleando como estándar de referencia a los pacientes que informaron en el estudio MOVID-19 su confirmación diagnóstica de COVID-19 mediante la PCR; se estimaron los VPP y los VPN para diferentes escenarios según el porcentaje de positividad, es decir, el porcentaje de resultados positivos del total de pruebas realizadas.

Finalmente, se comparó la capacidad de discriminación de cada uno de los cinco criterios mediante curvas de características operativas del receptor (conocidas como curvas ROC, por sus siglas en inglés) y se estimó si las diferencias de las curvas de los primeros cuatro criterios eran significativamente diferentes a la obtenida mediante el criterio 5 (resultado del presente estudio).

Para todos los análisis se utilizó el paquete estadístico Stata versión 15.1 (21).

El estudio MOVID-19 contó con la aprobación del Comité de Ética de Investigación en Seres Humanos (CEISH) de la Facultad de Medicina de la Universidad de Chile (Acta $\mathrm{N}^{\circ} 0150$, Proyecto $\mathrm{N}^{\circ}$ 037-2020). Se cumplieron todos los preceptos éticos internacionales, contenidos en la Declaración de Helsinki (22), y lo estipulado nacionalmente, según la Ley 20.120 (23) que regula la investigación biomédica en Chile. Cada participante firmó una declaración de consentimiento informado como prueba de su voluntariedad y conocimiento de las implicaciones de su participación. Para garantizar el anonimato de los participantes, se utilizó un identificador anónimo obtenido mediante una función de resumen irreversible. 
CUADRO 2. Variación de los síntomas y signos de la COVID-19 informados según los días de evolución de la enfermedad en la muestra estudiada $(n=1$ 995), Chile, 2020

\begin{tabular}{lccccccccc}
\multicolumn{3}{c}{ Variable } & \multicolumn{3}{c}{7 días } & \multicolumn{3}{c}{ 14 días } & \multicolumn{2}{c}{21 días } \\
& $n(\%)$ & OR & IC95\% & $n(\%)$ & OR & IC95\% & $n(\%)$ & OR & IC95\% \\
Anosmia & $189(9,47)$ & 8,00 & $5,34-11,99$ & $206(10,33)$ & 9,51 & $6,45-14,00$ & $222(11,13)$ & 9,69 & $6,58-14,27$ \\
Tos & $479(24,01)$ & 1,49 & $1,06-2,10$ & $562(28,17)$ & 1,52 & $1,08-2,12$ & $623(31,23)$ & 1,56 & $1,11-2,18$ \\
Diarrea & $245(12,28)$ & 1,47 & $1,00-2,17$ & $301(15,09)$ & 1,32 & $0,91-1,92$ & $319(15,99)$ & 1,29 & $0,89-1,88$ \\
Fiebre & $131(6,57)$ & 2,15 & $1,28-3,59$ & $150(7,52)$ & 2,79 & $1,71-4,56$ & $151(7,57)$ & 2,63 & $1,61-4,30$ \\
Odinofagia & $509(25,51)$ & 0,72 & $0,50-1,04$ & $604(30,28)$ & 0,63 & $0,44-0,90$ & $663(33,23)$ & 0,61 & $0,42-0,87$ \\
Cefalea & $722(36,19)$ & 1,12 & $0,80-1,57$ & $835(41,85)$ & 1,22 & $0,87-1,71$ & $949(47,57)$ & 1,24 & $0,89-1,74$ \\
Mialgia & $411(20,60)$ & 1,43 & $0,98-2,08$ & $478(23,96)$ & 1,44 & $1,00-2,09$ & $528(26,47)$ & 1,45 & $1,00-2,10$ \\
Dolor torácico & $176(8,82)$ & 1,79 & $1,10-2,93$ & $212(10,63)$ & 1,71 & $1,08-2,72$ & $226(11,33)$ & 1,76 & $1,12-2,79$ \\
Disnea & $165(8,27)$ & 0,82 & $0,48-1,38$ & $200(10,03)$ & 0,72 & $0,43-1,20$ & $225(11,28)$ & 0,70 & $0,42-1,17$ \\
Contacto con una & $475(23,81)$ & 2,89 & $2,16-3,87$ & $546(27,37)$ & 3,04 & $2,27-4,08$ & $598(29,97)$ & 3,12 & $2,32-4,18$ \\
persona positiva & & & & & & & &
\end{tabular}

Fuente: elaborado por los autores.

a $O$ R: razón de disparidad (odds ratio).

IC95\%: intervalo de confianza de $95 \%$.

\section{RESULTADOS}

El promedio de edad de los 2019 participantes fue de 43,0 años (desviación estándar $=12,7$ ); el 71,1\% correspondió a mujeres, $69,1 \%$ contaba con seguro de salud privado y $82,7 \%$ tenía educación profesional. Respecto a las comorbilidades, $13,6 \%$ presentaba hipertensión arterial y $8,4 \%$ padecía de alguna enfermedad respiratoria crónica (datos no presentados ${ }^{8}$ ).

Del total, 329 personas eran casos confirmados (PCR+) y 1690 se incluyeron como controles (PCR-). Los principales síntomas observados en los pacientes con PCR+ fueron: cefalea $(57,1 \%)$; tos $(45,3 \%)$; mialgia $(43,2 \%)$ y anosmia $(39,5 \%)$. Además, $51,7 \%$ manifestaron haber tenido contacto estrecho con una persona diagnosticada con COVID-19 (datos no presentados ${ }^{8}$ ).

Según el modelo logístico multifactorial, a los 7 días los pacientes con anosmia tenían una posibilidad de resultar positivos a la prueba de la PCR 8,00 veces mayor que los que no presentaban ese síntoma (OR = 8,00; IC95\%: 5,34-11,99). Esta relación fue de 2,15 veces mayor entre los que tenían fiebre (OR = 2,15; IC95\%: $1,28-3,59)$ y 2,89 veces mayor en los que habían tenido contacto estrecho con una persona diagnosticada con COVID-19 (OR = 2,89; IC95\%: 2,16-3,87). Otros signos y síntomas se presentaron como factores de riesgo para tener una prueba de la PCR+, pero con menor fuerza de asociación (cuadro 2).

\section{Propuesta del nuevo criterio de caso sospechoso (criterio 5)}

A partir de la regresión logística escalonada se seleccionaron siete variables: tos, diarrea, odinofagia, cefalea, fiebre, anosmia y contacto estrecho con una persona diagnosticada con COVID19. De ellas, el haber tenido contacto estrecho con una persona diagnosticada con COVID-19, la anosmia y la fiebre resultaron

\footnotetext{
\& Los cuadros suplementarios, junto con información adicional sobre el estudio, se pueden encontrar en el repositorio en https://github.com/ CoV-IMPACT-C/Diagnostic-criteria-COVID19-Chile/blob/404ce35067fdb95db3e3142404e4693450b18c55/Material\%20suplementario/Material\%20 suplementario.pdf
}

condiciones altamente específicas asociadas con la positividad a la PCR, por lo que se decidió considerarlas como suficientes en la nueva definición de caso sospechoso (criterio 5), sistematizada en el cuadro 1.

\section{Características diagnósticas de los criterios de caso sospechoso analizados}

Al calcular las propiedades diagnósticas de las definiciones de caso sospechoso analizadas - a partir de un porcentaje de positividad teórica a la prueba de la PCR de 16\%, correspondiente al porcentaje de personas con PCR+ en la muestra estudiada- se observó lo siguiente (cuadro 3):

Criterio 1, adoptado por el Ministerio de Salud de Chile el 23 de marzo (17). Logró una sensibilidad de 46,1\% y una especificidad de $89,0 \%$. Sus VPP y VPN fueron $44,6 \%$ y $89,6 \%$ respectivamente.

Criterio 2, propuesto por el Consejo Asesor COVID-19 de Chile el 26 de abril (18). Su sensibilidad estimada fue de $69,6 \%$, lo que representa una mayor capacidad de identificar correctamente los casos sospechosos que se confirmarían con un resultado $\mathrm{PCR}+$, en comparación con los criterios 1 y 3. Se observó una especificidad de solo 67,9\%, menor que las de esas dos definiciones. Consecuentemente, aunque su VPN aumentó a 92,0\%, el VPP disminuyó a 29,7\%.

Criterio 3, recomendado por la OMS en su actualización del 30 de abril (19). Permitió clasificar correctamente como sospechosos 169 de las 329 personas confirmadas mediante PCR+, para una sensibilidad de $51,4 \%$ y una especificidad de $85,7 \%$; su VPP fue de $41,2 \%$ y su VPN de $90,1 \%$.

Criterio 4, adoptado por el Ministerio de Salud de Chile el 30 de mayo (20). Presentó un comportamiento similar al criterio 2 , con una sensibilidad de $66,0 \%$, una especificidad de $69,0 \%$; su VPP fue de $29,3 \%$ y su VPN de $91,2 \%$.

Criterio 5, propuesto por esta investigación. Presentó los valores de sensibilidad y VPN más altos de las definiciones de caso sospechoso analizadas: 78,4\% (IC95\%: 73,6\%-82,7\%) y 93,6\% (IC95\%: 91,9\%-94,9\%), respectivamente. En comparación con el criterio 4 (vigente en Chile) —incluso al considerar 
CUADRO 3. Propiedades diagnósticas de los cinco criterios de caso sospechoso de COVID-19 analizados ${ }^{\text {, }}$, según el resultado de la prueba de la reacción en cadena de la polimerasa (PCR), Chile, 2020

\begin{tabular}{|c|c|c|c|c|c|c|c|c|c|c|}
\hline \multirow{3}{*}{$\begin{array}{c}\text { Prueba de la PCR } \\
\text { confirmada }\end{array}$} & \multicolumn{2}{|c|}{ Criterio 1} & \multicolumn{2}{|c|}{ Criterio 2} & \multicolumn{2}{|c|}{ Criterio 3} & \multicolumn{2}{|c|}{ Criterio 4} & \multicolumn{2}{|c|}{ Criterio 5} \\
\hline & \multicolumn{2}{|c|}{ Sospechoso $0^{b}$} & \multicolumn{2}{|c|}{ Sospechoso } & \multicolumn{2}{|c|}{ Sospechoso } & \multicolumn{2}{|c|}{ Sospechoso } & \multicolumn{2}{|c|}{ Sospechoso } \\
\hline & Sí & No & Sí & No & Sí & No & Sí & No & Sí & No \\
\hline Sí & 149 & 174 & 229 & 100 & 169 & 160 & 217 & 112 & 258 & 71 \\
\hline No & 185 & 1503 & 542 & 1148 & 241 & 1449 & 524 & 1166 & 660 & 1030 \\
\hline Total & 334 & 1677 & 771 & 1248 & 410 & 1609 & 741 & 1278 & 918 & 1101 \\
\hline Sensibilidad, \% (IC95\%) & \multicolumn{2}{|c|}{$46,1(40,6-51,7)$} & \multicolumn{2}{|c|}{$69,6(64,3-74,5)$} & \multicolumn{2}{|c|}{$51,4(45,8-56,9)$} & \multicolumn{2}{|c|}{$66,0(60,6-71,1)$} & \multicolumn{2}{|c|}{$78,4(73,6-82,7)$} \\
\hline VPN $^{d}, \%(I C 95 \%)$ & \multicolumn{2}{|c|}{$89,6(88,1-91,0)$} & \multicolumn{2}{|c|}{$92,0(90,3-93,4)$} & \multicolumn{2}{|c|}{$90,1(88,5-91,5)$} & \multicolumn{2}{|c|}{$91,2(89,6-92,7)$} & \multicolumn{2}{|c|}{$93,6(91,9-94,9)$} \\
\hline
\end{tabular}

Fuente: elaborado por los autores.

Nota. IC95\%: intervalo de confianza de $95 \%$

Criterio 1: adoptado por el Ministerio de Salud de Chile el 23 de marzo (17); Criterio 2: recomendado por el Consejo Asesor CoVID-19 de Chile el 26 de marzo (18); Criterio 3: recomendado por la Organización Mundial de la Salud en su actualización del 30 abril (19); Criterio 4: adoptado por el Ministerio de Salud de Chile el 30 de mayo (20); Criterio 5: nuevo criterio propuesto.

Ocho participantes no tenian la información completa.

VPP: Valor predictivo positivo para un porcentaje de positividad a la prueba de la PCR de $16 \%$

${ }^{-}$VPN: Valor predictivo negativo para un porcentaje de positividad a la prueba de la PCR de $16 \%$.

FIGURA 1. Comparación de los valores predictivos de los criterios 4 y 5 , según el porcentaje de positividad

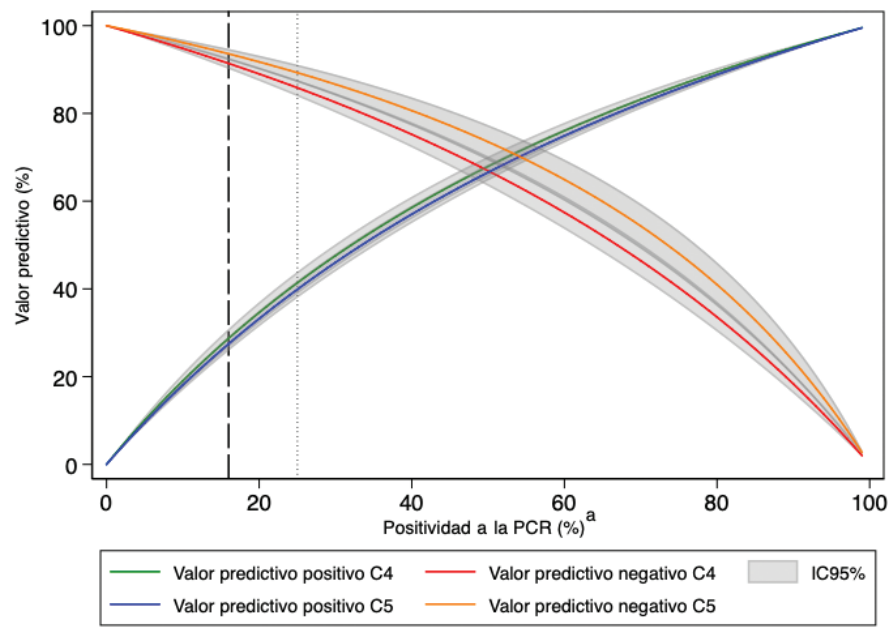

Fuente: elaborado por los autores a partir de los datos obtenidos del estudio Monitoreo Nacional de Síntomas y Prácticas COVID-19 en Chile (MOVID-19).

Nota: C4: Criterio 4 (Ministerio de Salud de Chile); C5: Criterio 5 (nuevo criterio propuesto); IC95\%: intervalo de a Proporción de casos positivos a la reacción en cadena de la polimerasa.

escenarios de mayor prevalencia en la población y aumento del porcentaje de positividad de las pruebas de la PCR producto de una mayor transmisión comunitaria-, el criterio 5 logró identificar correctamente una mayor proporción de verdaderos negativos, particularmente cuando el porcentaje de positividad sobrepasa el 15\% (figura 1). Esto tiene una gran importancia en el control de brotes epidémicos; no obstante, disminuyó ligeramente el VPP (capacidad de detectar correctamente los casos verdaderamente positivos), independientemente de la prevalencia en la población.

Para finalizar, el análisis de las curvas ROC a partir de la sensibilidad y la especificidad de los cinco criterios analizados (figura 2) mostró que la mayor capacidad de discriminación, según el área bajo la curva, corresponde al criterio 5 (0,6977; IC95\%: 0,67-0,72), aunque sin diferencias estadísticamente significativas $(p=0,06)$ con los otros cuatro criterios analizados.
FIGURA 2. Comparación de la especifidad de todos los criterios, según las curvas ROC

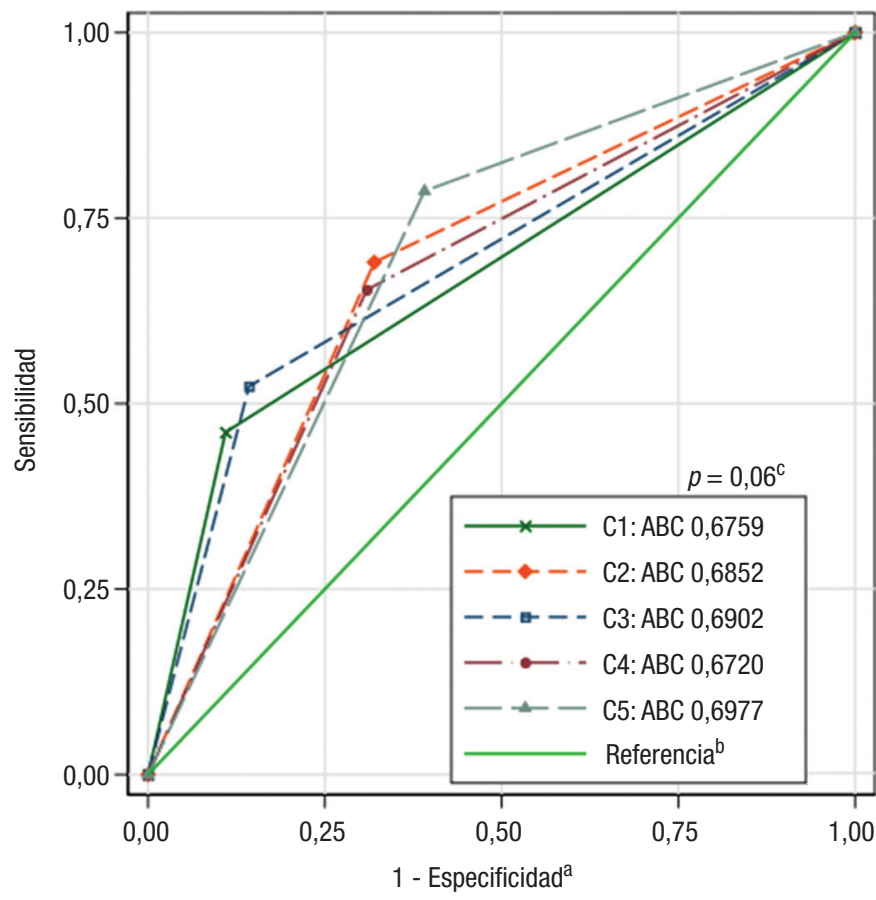

Fuente: elaborado por los autores a partir de los datos obtenidos del estudio Monitoreo Nacional de Síntomas y Prácticas COVID-19 en Chile (MOVID-19)

Nota: C1: Criterio 1 (Ministerio de Salud de Chile); C2: Criterio 2 (Recomendación del Consejo Asesor CoVID-19 de Chile); C3: Criterio 3 (Organización Mundial de la Salud); C4: Criterio 4 (Ministerio de Salud de Chile); C5: Criterio 5 (nuevo criterio propuesto); ABC: área bajo la curva.

- Referencia: capacidad nula de distinguir entre quienes presentan o notivos. - No se observaron diferencias estadísticamente significativas $(p=0,06)$ al comparar el ABC del criterio 5 con los otros cuatro criterios.

\section{DISCUSIÓN}

Al comparar las propiedades diagnósticas de los cinco criterios de definición de caso sospechoso analizados, se observó que tanto el establecido en Chile en el mes de marzo (criterio 1) como el propuesto por la OMS (criterio 3) presentaron valores de especificidad adecuados, por encima del $85 \%$, pero valores 
de sensibilidad bajos, cercanos al 50\%. Aunque al aplicar los criterios 2 y 4 (propuesto por el Consejo Asesor y el empleado en la actualidad, respectivamente) la sensibilidad aumentó a más de $66 \%$, los valores de especificidad no llegaron al $70 \%$, muy por debajo de los dos primeros criterios analizados.

Según el criterio 4, aplicado a partir del mes de mayo, los casos sospechosos se definen por la presencia de al menos 2 de 11 síntomas de COVID-19, independientemente de cuáles sean. Sin embargo, al evaluar la asociación de los síntomas con los resultados de la PCR+ se observa que la anosmia y la fiebre presentan una fuerte asociación.

El criterio 5, propuesto en esta investigación, incorpora ambas variables como indicadores de sospecha por sí solos sin otro síntoma o condición que deba estar presente-, lo que eleva la sensibilidad de la definición clínica de caso sospechoso.

Esa fuerte asociación entre la confirmación de la COVID-19 y la anosmia o la fiebre ha sido documentada por otros investigadores (24-26). En un estudio con cohortes del Reino Unido y los Estados Unidos de América, Menni y colaboradores (24) observaron que la pérdida del olfato y el gusto, conjuntamente con otros síntomas más frecuentes como la fiebre y la tos, son buenos predictores de la COVID-19. Asimismo, Roland y colaboradores (25) encontraron mediante una encuesta en línea que recababa información sobre los resultados PCR+ una sensibilidad cercana al $70 \%$ al considerar cambios en el olfato o el gusto y fiebre como predictores de la COVID-19.

En el presente estudio también se demostró la importancia de considerar como caso sospechoso a todas las personas con antecedente de haber tenido contacto estrecho con alguna persona diagnosticada con la COVID-19. En Chile, mediante el decreto promulgado el 7 de junio (27), se estableció la cuarentena preventiva para quienes hayan tenido este tipo de contacto, en coherencia con las medidas que se han implementado en muchos países (28). Sin embargo, estas acciones deben acompañarse de estrategias que permitan fortalecer la trazabilidad de los contactos para disminuir la propagación de la enfermedad (29).

La incorporación de la fiebre o la anosmia como síntomas suficientes para considerar un caso sospechoso en el criterio 5, con la adición como indicador suficiente del antecedente de haber tenido contacto estrecho con una persona con COVID-19 confirmada mediante la PCR, permitiría elevar la sensibilidad del criterio vigente en Chile en 12,4 puntos porcentuales. Si bien el criterio 5 tiene la menor especificidad y el VPP más bajo, su mayor sensibilidad permitiría identificar una mayor cantidad de casos posibles y ayudar a cortar la cadena de transmisión precozmente. Esto es importante mientras se mantienen los brotes y se establece una mejor respuesta diagnóstica confirmatoria y compensaría la pérdida de especificidad $(8,29)$. En este contexto, las consecuencias de un falso positivo pueden considerarse menos preocupante que permitir un falso negativo, dado que la valoración del riesgo al que se somete a una persona aislada innecesariamente (falso positivo) es, sin dudas, menor que las consecuencias para la persona y la comunidad de no aislar oportunamente a alguien enfermo por haberlo clasificado de manera incorrecta como negativo (falso negativo), debido al elevado poder de transmisión del virus. De manera similar, es preferible utilizar un criterio con mayor sensibilidad para guiar decisiones clínicas de aislamiento en contextos de escasez de capacidad o retrasos en los resultados de laboratorio.
El 1 de octubre se realizó una nueva actualización de los criterios aplicados en Chile (30), en la cual se modifica la definición de caso probable diagnosticado por síntomas para añadir a las personas que "presenten pérdida brusca y completa del olfato (anosmia) o del gusto (ageusia) sin causa que lo explique", pero se mantiene la definición de caso sospechoso establecida en mayo. Por definición, los casos probables se deben manejar como casos confirmados, lo que implica la entrega de una licencia médica, el aislamiento, y la identificación y cuarentena de sus contactos estrechos. Incluir la presencia de anosmia y ageusia como criterios por sí solos para declarar a una persona como caso probable por síntomas simplifica la identificación de casos y su manejo, al focalizar la atención en los síntomas que por sí solos permiten identificar con mayor certeza los casos de COVID-19. En esas circunstancias, se debe tener siempre en cuenta que la especificidad del criterio 5 (que incluye la anosmia como síntoma único suficiente) disminuye en relación al criterio 4, actualmente vigente.

Investigaciones realizadas en epidemias anteriores han confirmado la importancia de contar con criterios sólidos de caso sospechoso, que permitan fortalecer la vigilancia de la enfermedad $(8,31,32)$. A medida que aumenta el control de los brotes y disminuye la incidencia de casos, se hace fundamental identificar con mayor precisión a las personas infectadas y enfermas, ya que, como ha ocurrido con otras enfermedades infecciosas, es la única forma de saber si continúa la transmisión en el área en cuestión (33). Si bien el criterio 5 tiene una capacidad de predicción similar al criterio 4, presenta un mayor VPN —es decir, identifica como negativas a más personas sin la enfermedad en los diferentes escenarios de positividad-, lo que permite focalizar los recursos asociados a la confirmación de los casos en las personas con mayor posibilidad de presentar PCR+.

$\mathrm{Al}$ analizar estos resultados se deben tomar en cuenta algunas limitaciones. Se evaluó el rendimiento diagnóstico y la capacidad predictiva de los criterios de caso sospechoso en una submuestra del panel del estudio MOVID-19 con participantes que informaron un resultado PCR+. Por lo tanto, la muestra estudiada aquí está constituida por personas que entregaron información respecto a sus signos y síntomas mediante un instrumento de autoinforme voluntario en línea, lo que puede generar un sesgo a favor de las personas más comprometidas pero menos representativas de la población general. Además, esta muestra tiene una sobrerrepresentación de mujeres y de personas con un nivel educacional alto (profesional) debido a la estrategia empleada de convocar a voluntarios, lo que puede generar otro sesgo de selección. Sin embargo, en el contexto actual, una muestra con estas características permite tener una mayor confiabilidad en la predicción de la positividad debido a que se trata de una población más comprometida con la generación de evidencias y sensibilizada con el tema de estudio (24).

Por otra parte, para el análisis se consideró el porcentaje de positividad de la muestra estudiada $(16 \%)$, diferente del observado en la población general en Chile, que en julio del 2020 era de cerca de $25 \%$ (34). No obstante, los valores predictivos se estimaron para diferentes escenarios de positividad, lo que permite analizar el rendimiento del criterio a medida que evoluciona la pandemia (35).

En conclusión, el empleo del criterio 5 permitió identificar los casos sospechosos a la COVID-19 con mayor sensibilidad, algo fundamental para controlar la propagación de la pandemia. El monitoreo constante de los signos y síntomas que predicen 
con mayor certeza la enfermedad en las distintas etapas de la pandemia debe contribuir a establecer estrategias diferenciadas acordes a cada contexto. En Chile y el mundo se requiere de un criterio altamente sensible que permita detectar la mayor cantidad de casos sospechosos, a partir de signos y síntomas con mayor capacidad predictiva, para propiciar el aislamiento precoz y la trazabilidad de los contactos. En una fase de mayor control de la enfermedad, podría optarse por criterios más específicos que permitan una mejor distribución de los recursos asistenciales.

Contribución de los autores. JA contribuyó a la interpretación de los datos, redactó el borrador del manuscrito y dirigió la redacción del manuscrito final; DD contribuyó al análisis e interpretación de los datos y la redacción del borrador del manuscrito; MJM y SM contribuyeron al diseño, el análisis y la interpretación de los datos; CC contribuyó al levantamiento, la concepción, el diseño y la interpretación de los datos; MFR, ESR, JG, TA y MPB contribuyeron a la revisión del análisis de los datos y su interpretación. Todos los autores revisaron críticamente el manuscrito y dieron su aprobación a la versión final aceptada.
Agradecimientos. A Mónica Gerber, José Tomás Atria, Ismael Puga y Pablo Soto por su activa participación en la conceptualización del estudio MOVID-19 y el levantamiento de la información, y a Carolina Nazzal por sus oportunos comentarios a las versiones iniciales del análisis.

\section{Conflictos de intereses. Ninguno.}

Financiación. Este proyecto fue financiado mediante aportes de la Universidad de Chile, la Universidad Diego Portales, el Colegio Médico de Chile, A.G., el proyecto "Impacto del COVID-19 en Chile. Una evaluación transdisciplinaria de la respuesta a la pandemia y sus consecuencias" (ANID-COVID 0960) y la Vicerrectoría de Vinculación con el Medio, de la Universidad San Sebastián, a través del fondo concursable para proyectos colaborativos 2020 (ID 1768).

Declaración. Las opiniones expresadas en este artículo son responsabilidad de los autores y no reflejan necesariamente los criterios ni la política de la Revista Panamericana de Salud Pública / Pan American Journal of Public Health y/o de la Organización Panamericana de la Salud.

\section{REFERENCIAS}

1. Zhu N, Zhang D, Wang W, Deng JW, Zheng L, Zhu HH, et al. A novel coronavirus from patients with pneumonia in China, 2019. N Engl J Med. 2020;382:727-33. doi:10.1056/NEJMoa2001017

2. Johns Hopkins University \& Medicine. Coronavirus Resource Center [Internet] [citado el 9 de julio del 2020]. Disponible en: https:/ / coronavirus.jhu.edu/map.html

3. Li Q, Guan X, Wu P, Wang X, Zhou L, Tong Y, et al. Early transmission dynamics in Wuhan, China, of novel coronavirus-infected pneumonia. N Engl J Med. 2020;382:1199-07. doi:10.1056/NEJMoa2001316

4. Lauer SA, Grantz KH, Bi Q, Jones FK, Zheng X, Meredith HR, et al. The incubation period of coronavirus disease 2019 (COVID-19) from publicly reported confirmed cases: Estimation and application. Ann Intern Med. 2020;172:577-82. doi: 10.7326/M20-0504

5. Wynants L, Van Calster B, Collins GS, Riley RD, Heinze G, Schuit E, et al. Prediction models for diagnosis and prognosis of COVID19 infection: Systematic review and critical appraisal. Br Med J. 2020;369:1-24. doi:10.1136/bmj.m1328

6. Rothan HA, Byrareddy SN. The epidemiology and pathogenesis of coronavirus disease (COVID-19) outbreak. J Autoimmun. 2020;109:102433. doi:10.1016/j.jaut.2020.102433

7. Nadri J, Sauvageot D, Njanpop-Lafourcade BM, Baltazar CS, Kere $A B$, Bwire G, et al. Sensitivity, specificity, and public-health utility of clinical case definitions based on the signs and symptoms of cholera in Africa. Am J Trop Med Hyg. 2018;98:1021-30. doi:10.4269/ ajtmh.16-0523

8. Hsu CH, Champaloux SW, Keïta S, Martel L, Bilivogui P, Knust B, et al. Sensitivity and specificity of suspected case definition used during West Africa Ebola epidemic. Emerg Infect Dis. 2018;24:9-14. doi:10.3201/eid2401.161678

9. Zhang J, WuS, Xu L. Asymptomatic carriers of COVID-19 as a concern for disease prevention and control: more testing, more follow-up. Biosci Trends. 2020;14(3):206-8. doi:10.5582/bst.2020.03069

10. Oran DP, Topol EJ. Prevalence of asymptomatic SARS-CoV-2 infection: A narrative review. Ann Intern Med. 2020;M20:3012. doi:10.7326/M20-3012

11. Hellewell J, Abbott S, Gimma A, Bosse NI, Jarvis CI, Russell TW, et al. Feasibility of controlling COVID-19 outbreaks by isolation of cases and contacts. Lancet Glob Health. 2020;8:488-96. doi:10.1016/ S2214-109X(20)30074-7
12. Cheng H, Jian S, Liu D, Ng TC, Huang WT, Lin HH, et al. Contact tracing assessment of COVID-19 transmission dynamics in Taiwan and risk at different exposure periods before and after symptom onset. JAMA Intern Med. 2020;180(9):1156-63. doi:10.1001/ jamainternmed.2020.2020

13. Liang W, Liang H, Ou L, Chen B, Chen A, Li C, et al. Development and validation of a clinical risk score to predict the occurrence of critical illness in hospitalized patients with COVID-19. JAMA Intern Med. 2020;180(8):1081-9. doi:10.1001 / jamainternmed.2020.2033

14. Ministerio de Salud de Chile. Informe epidemiológico enfermedad por COVID-19 Chile 30-03-2020 [Internet] [citado el 16 de junio del 2020]. Disponible en: https://www.minsal.cl/wp-content/ uploads/2020/03/INFORME_EPI_COVID19_20200330.pdf

15. Ministerio de Salud de Chile. Informe epidemiológico $\mathrm{N}^{\mathrm{o}} 31$ enfermedad por SARS-CoV-2 (COVID-19) Chile 05-07-2020. [Internet] [citado el 16 de junio del 2020]. Disponible en: https:/ / www.minsal. $\mathrm{cl} /$ wp-content/uploads/2020/07/InformeEPI050720ok.pdf

16. Ministerio de Salud de Chile. Informe epidemiológico $\mathrm{N}^{\circ} 61$ enfermedad por SARS-CoV-2 (COVID-19) Chile 19-10-2020 [Internet] [citado el 22 de octubre del 2020]. Disponible en: https: / /www.minsal.cl/wp-content/uploads/2020/10/Informe-Epidemiologico-61. pdf

17. Ministerio de Salud de Chile, División de Planificación Sanitaria, Departamento de Epidemiología. Ordinario B51-933, 23 de marzo 2020. Actualización de definición de caso sospechoso para vigilancia epidemiológica ante brote COVID-19 [citado el 16 de junio del 2020]. Disponible en: https://www.minsal.cl/wp-content/ uploads/2020/04/Ord.-B51-N\%C2\%BA933.pdf

18. República de Chile, Consejo Asesor COVID-19. Estrategias para aumentar la detección de SARS-CoV-2 en Chile [Internet] [citado el 16 de junio del 2020]. Disponible en: https://drive.google.com/ file/d/1ppSNUnFfuVKoHrN0_XMaNXVaNMP0VqSz/view

19. World Health Organization. Coronavirus disease 2019 (COVID19). Situation report-101 [Internet] [citado el 16 de junio del 2020]. Disponible en: https://www.who.int/docs/default-source/corona viruse / situation-reports / 20200430-sitrep-101-covid-19.pdf? sfvrsn=2ba4e093_2

20. Ministerio de Salud de Chile. Resolución, dispone medidas sanitarias que indica por brote de COVID-19. Santiago: Diario Oficial de 
la República de Chile, 2020 mayo 30 [Internet] [citado el 16 de junio del 2020]. Disponible en: https://www.minsal.cl/wp-content/ uploads/2020/05/Resoluci\%C3\%B3n.pdf

21. StataCorp. Stata statistical software: Release 15. College Station, TX: StataCorp LLC; 2017.

22. Declaración de Helsinki. Principios éticos para las investigaciones médicas en seres humanos. Asociación Médica Mundial, 59. Asamblea General, Seúl, Corea; 2008.

23. Ministerio de Salud de Chile, Subsecretaría de Salud Pública. Ley 20120, sobre la investigación científica en el ser humano, su genoma y prohíbe la clonación humana. Santiago: Diario Oficial de la República, 2006 septiembre 22.

24. Menni C, Valdes AM, Freidin MB, Sudre $\mathrm{CH}$, Nguyen LH, Drew DA, et al. Real-time tracking of self-reported symptoms to predict potential COVID-19. Nat Med. 2020;1037-40 [citado el 16 de junio del 2020]. Disponible en: https:/ / doi.org/10.1038/s41591-020-0916-2

25. Roland LT, Gurrola JG 2nd, Loftus PA, Cheung SW, Chang JL. Smell and taste symptom-based predictive model for COVID-19 diagnosis. Int Forum Allergy Rhinol. 2020;10(7):832-8. doi:10.1002/ alr.22602

26. Menni C, Sudre CH, Steves CJ, Ourselin S, Spector TD. Quantifying additional COVID-19 symptoms will save lives. Lancet. 2020;395:e107-8. doi:10.1016/S0140-6736(20)31281-2

27. Ministerio de Salud de Chile. Resolución, dispone medidas sanitarias que indica por brote de COVID-19. Santiago: Diario Oficial de la República de Chile; 2020 junio 9 [Internet] [citado el 16 de junio del 2020]. Disponible en: https://www.minsal.cl/wp-content/ uploads/2020/06/1771191.pdf

28. Centers for Disease Control and Prevention. Active monitoring of persons exposed to patients with confirmed COVID-19 - United States, January-February 2020 [Internet] [citado el 22 de junio del 2020]. Disponible en: https://www.cdc.gov/mmwr/volumes/69/ $\mathrm{wr} / \mathrm{mm} 6909 \mathrm{e} 1 . \mathrm{htm}$

29. Bi Q, Wu Y, Mei S, Ye C, Zou X, Zhang Z, et al. Epidemiology and transmission of COVID-19 in 391 cases and 1286 of their close contacts in Shenzhen, China: A retrospective cohort study. Lancet Infect Dis. 2020;911-9. doi:10.1016/S1473-3099(20)30287-5

30. Ministerio de Salud de Chile, División de Planificación Sanitaria, Departamento de Epidemiología. Ordinario B51-4239, 1 de octubre 2020. Actualización de definición de caso sospechoso, confirmado y probable para vigilancia epidemiológica ante pandemia COVID-19 [Internet] [citado el 16 de junio del 2020]. Disponible en: https:// www.minsal.cl/wp-content/uploads/2020/10/201006-Definici\% C3\%B3n-de-caso-sospechoso.pdf

31. Oliveira SA de, Camacho LAB, Pereira ACM, Setúbal S, Nogueira RMR, Siqueira MM. Assessment of the performance of a definition of a suspected measles case: implications for measles surveillance. Rev Panam Salud Publica. 2006;19:229-35.

32. Thriemer K, Ley B, Ame SS, Deen JL, Pak JD, Chang NY, et al. Clinical and epidemiological features of typhoid fever in Pemba, Zanzibar: Assessment of the performance of the WHO case definitions. PLoS One. 2012;7(12):e51823. doi:10.1371/journal.pone.0051823

33. Nsubuga F, Ampaire I, Kasasa S, Luzze H, Kisakye A. Positive predictive value and effectiveness of measles case-based surveillance in Uganda, 2012-2015. PloS One. 2017;12:1-8. doi: https://doi. org/10.1371/journal.pone.0184549

34. Gobierno de Chile. Cifras oficiales COVID-19 [Internet] [citado el 6 de julio del 2020]. Disponible en: https: / / www.gob.cl/coronavirus / cifrasoficiales /

35. Hernaez R, Thrift AP. High negative predictive value, low prevalence, and spectrum effect: Caution in the interpretation. Clin Gastroenterol Hepatol. 2017;15(9):1355-8. Disponible en: doi: 10.1016/j.cgh.2017.05.002

Manuscrito recibido el 21 de julio del 2020. Aceptado para publicación, tras revisión, el 22 de septiembre del 2020.

\section{Diagnostic properties of case definitions of suspected COVID-19 in Chile, 2020}

ABSTRACT Objective. Compare the diagnostic properties of five case definitions of suspected COVID-19 that were used or proposed in Chile during the first eight months of the pandemic.

Methods. An analysis was done of the diagnostic properties (sensitivity, specificity, and positive and negative predictive values) of three case definitions of suspected COVID-19 used in Chile between March and October 2020, as well as two alternative proposed definitions. The sample was 2,019 people with known results for the polymerase chain reaction (PCR) test for SARS-CoV-2. Stepwise logistic regression was used to develop criterion 5, optimizing sensitivity and specificity values. Multifactor logistic regression was used to explore the association between demographic variables, symptoms and signs, and PCR positivity. Different positivity scenarios were analyzed and ROC curves were compared.

Results. The presence of anosmia (OR = 8.00; Cl95\%: 5.34-11.99), fever ( $\mathrm{OR}=2.15 ; \mathrm{Cl} 95 \%$ : 1.28-3.59), and having been in close contact with a person sick with COVID-19 (OR = 2.89; CI95\%: 2.16-3.87) were associated with a positive PCR result. According to the analysis of the ROC curve, criterion 5 had the highest capacity for discrimination, although there were no significant differences with the other four criteria.

Conclusions. Criterion 5-based on anosmia, close contact with people with COVID-19, and fever as sufficient unique elements-was the most sensitive in identifying suspected cases of COVID-19, a key aspect in controlling the spread of the pandemic.

Keywords $\quad$ Coronavirus infections; SARS virus; molecular diagnostic techniques; Chile. 


\section{Características diagnósticas das definições de caso suspeito de COVID-19 no Chile, 2020}

RESUMO Objetivo. Comparar as características diagnósticas de cinco critérios das definições de caso suspeito de COVID-19 usados ou propostos no Chile nos oito primeiros meses de pandemia.

Métodos. Foram avaliadas as características diagnósticas (sensibilidade, especificidade e valores preditivos positivo e negativo) de três critérios das definições de caso suspeito de COVID-19 usados no Chile entre março e outubro de 2020 e de duas alternativas propostas para definição de caso. A amostra do estudo consistiu 2019 pessoas com resultados conhecidos no exame de reação em cadeia da polimerase (PCR) para SARS-CoV-2. Para elaborar o critério 5, uma regressão logística com método stepwise foi realizada otimizando os valores de sensibilidade e especificidade. A associação entre variáveis demográficas, sintomas e sinais e resultado positivo no exame de PCR foi testada em um modelo de regressão logística multifatorial. Situações diferentes de resultado positivo foram testadas com uma análise comparativa das curvas ROC.

Resultados. Presença de anosmia (OR 8,00; IC95\% 5,34-11,99), febre (OR 2,15; IC95\% 1,28-3,59) e contato próximo anterior com uma pessoa com COVID-19 (OR 2,89; IC95\% 2,16-3,87) foram associados a um resultado positivo no exame de PCR. De acordo com a análise das curvas ROC, o critério 5 demonstrou maior capacidade discriminatória, apesar de não existir diferença significativa com os outros quatro critérios.

Conclusão. O critério 5 - presença de anosmia, febre e contato próximo com uma pessoa com COVID-19 como elementos únicos e suficientes - demonstrou maior sensibilidade para identificar casos suspeitos de COVID-19, o que é fundamental para controlar a disseminação da pandemia.

Palavras-chave Infecções por coronavirus; vírus da SARS; técnicas de diagnóstico molecular; Chile. 